\title{
Teaching our learners to swim: attachment theory and the educator's role in promoting mastery in pediatric radiology training
}

\author{
Peter L. Loper Jr. ${ }^{1}$ Janet R. Reid ${ }^{2}$ (D) \\ Received: 21 April 2020 / Revised: 18 May 2020 / Accepted: 24 June 2020 / Published online: 21 July 2020 \\ (C) Springer-Verlag GmbH Germany, part of Springer Nature 2020
}

Dr. Richard Gunderman once quoted Nicolas Chamfort as saying, "To succeed as leaders, radiologists must understand psychology" [1]. In other words, an understanding of psychology is as important as our radiology expertise if we are to succeed as teachers and leaders of our trainees. To start, the famous psychiatrist and psychoanalyst John Bowlby was the predecessor and mentor to the prolific psychologist Mary Ainsworth; together, their decades of research on the psychology of human development confirmed that perhaps the most important element in an individual's developmental process is the presence of a secure attachment.

So, what is "secure attachment" and what does this have to do with teaching adult learners? A secure attachment occurs when an experienced person provides a secure base from which an inexperienced person can explore and a safe haven to which this inexperienced person can return for support. In fact, as noted by Ainsworth, the presence of a secure attachment "can tip the balance in favor of exploring the novel rather than avoiding it or withdrawing from it" [2].

Take for instance a young child who is learning to swim. Standing at the edge of the pool hesitantly looking down into the water, she is dripping wet from a morning spent swimming in and out of her mother's arms. She now wants to explore further, to try something new. She can run, walk up and down stairs, and she can hop on two feet. But swimming is a brandnew experience, and she has never jumped into the pool by herself.

Her mother, the secure base, is thoughtfully positioned in the water a few feet away, and observes as her child explores. The child crouches at the edge of the pool, glancing at her

Janet R. Reid

reidj@email.chop.edu

1 Department of Neuropsychiatry and Behavioral Science, University of South Carolina School of Medicine, Columbia, SC, USA

2 Department of Radiology, Children's Hospital of Philadelphia, 3401 Civic Center Blvd., Philadelphia, PA 19104, USA mother for reassurance. She leans forward preparing to leap, but before she can jump her momentum carries her headfirst into the pool. She emerges from the water, wide-eyed, arms flailing with her goggles halfway off of her face. As soon as she can muster a breath, she lets out a scream of desperation as her mother, now the safe haven, scoops her out of the water and to safety.

Consistent with this story, we often think of attachment as relevant only during childhood. However, as Bowlby pointed out, the core components of the caregiver-attachment systems necessary to promote growth and development are active throughout an individual's life [3, 4]. In childhood, we instinctually seek proximity to our primary attachment figure to support the exploration necessary for mastery of our foundational developmental tasks. However, as adults we retain the same instinct to seek proximity to a person with experience to support our approach and exploration of novelty [5]. Human beings, regardless of age, have the fundamental biological requirement of a secure base and safe haven to master any task requiring the linear acquisition of complex new skills and competencies.

The novelty of new experiences during residency and fellowship training, particularly in a specialty such as pediatric radiology, cannot be overstated. With this in mind, the story about the little girl learning to swim could very easily be rewritten. Take for instance the pediatric radiology trainee learning to do a new procedure. Standing beside the fluoroscopy machine, hesitantly looking down at her patient, she is brimming with confidence from a week spent on body MRI under the supervision of her attending physician. She now wants to explore further, to try something new. She is comfortable with fluoroscopy. She understands indications for a given exam, and she is proficient at acquiring and interpreting images. But a fluoroscopic air enema for intussusception reduction is a new experience, and she has never done this.

In this version of the story, the young trainee is approaching novelty, and she is preparing to explore; so who, then, is her secure base and safe haven? As attending clinical 
faculty and educators, we are. The story about the pediatric radiology trainee could continue like this:

Her attending, the secure base, is thoughtfully positioned behind her and observes as the trainee explores. The trainee inserts and tapes the rectal catheter in place, turning to her attending and the lead technologist for reassurance. With the help of the patient's mother, she turns the child prone and snaps a scout image. Turning to the monitor, she begins squeezing the sphygmomanometer to insufflate the bowel and, to her dismay, the rectal catheter slips out. The trainee flounders to grab the catheter. The attending clinician, now the safe haven, swoops in to re-insert the catheter and to teach, without judgment, appropriate replacement and taping to ensure that it remains in place.

When we supervise and teach our inexperienced residents and fellows, we are engaging our biologically engrained caregiver-attachment systems. Our learners' uncertainty and angst in new scenarios, especially when they are dangerous or high-stakes, trigger their evolutionary drive for care-seeking and reassurance, and require a secure base and safe haven to promote the approach and exploration necessary for their progressive development to mastery.

It can be a powerful exercise to use the frame of attachment to understand our primary responsibilities as teachers. Clearly, our adult learners' personal characteristics play a very important role in how willing they are to approach and explore novelty. However, we have no control over our learners' innate temperaments. If we think of the teacher-learner relationship as interactional, we are responsible for maximizing our function as an attachment figure. Fostering independence instead of dependence, providing reassurance during exploration, and giving nonjudgmental support amid failures are the vital actions necessary to promote learner mastery. If we fail to demonstrate any of these attributes, we compromise the secure base and safe haven, and inhibit our trainees' development.

So, what happens to our residents and fellows in the absence of the secure base and safe haven? Again, there is a biological function of the caregiver-attachment systems to provide security and safety when one is confronting the threat of novelty, so in the absence of these, their fear systems activate. They freeze, flee or withdraw and avoid exploration. They become unable to make clinical decisions independent of the input of their attendings, or they become unwilling to try new procedures. Or sometimes they fight, and they defend their deep-seated insecurities by challenging authority, challenging limits, and by exhibiting intense distress when their efficacy is questioned. And so often when our residents exhibit these behaviors, we chastise and criticize, and even impugn their character. But how often do we take a step back to ask whether we as teachers have provided the secure base and safe haven necessary to support their growth and development?
Returning to the story of the little girl learning to swim: After a few minutes spent in the safe haven of her mother's arms, the child ventures back to the edge of the pool to explore once again. Mother resumes her role as secure base and takes her position a few feet away. This time the child successfully jumps in, managing to keep her head above water. By the end of the day, she is jumping into the pool to the point of full submersion and squealing with delight as she surfaces. By the end of the summer she has shed her lifejacket and water wings and is swimming like a fish while her mother watches from a lounge chair at poolside.

In our fast-paced health care environment, the waters are choppy, and the pool is deep. Now, more than ever, our adult learners need a secure attachment so that they can learn to swim. Like the mother in the pool, as teachers for our adult learners, we must provide space for our trainees' exploration, reassurance as they explore, and support when they struggle so that they are willing to try again. When we provide the wisdom and authority of a secure base, our learners will eagerly approach and explore the pool. When we offer the support and kindness of a safe haven, our learners will be more resilient and return to poolside when they fall during their exploration. When we as educators commit to providing a meaningful "educator-attachment system," our learners will master the swells of our rapidly changing field. More important, as masters of their craft they will be equipped to one day provide secure attachment for subsequent generations of trainees who will continue the legacy of our prestigious and noble discipline.

\section{Compliance with ethical standards}

Conflicts of interest None

\section{References}

1. Gunderman R (2003) Leadership and psychological development. Radiology 228:617

2. Ainsworth MD, Bell SM (1970) Attachment, exploration, and separation: illustrated by the behavior of one-year-olds in a strange situation. Child Dev 41:49-67

3. Bell DC (2009) Attachment without fear. J Fam Theory Rev 1:177197

4. Bowlby J (1982) Attachment and loss, vol. 1, 2nd edn. Basic Books, New York, p 436

5. Fleming $\mathrm{T}$ (2008) A secure base for adult learning: attachment theory and adult education. In: adult learner: the Irish journal of adult and community education, pp 33-53

Publisher's note Springer Nature remains neutral with regard to jurisdictional claims in published maps and institutional affiliations. 